\title{
COLORADOSCHOOLOFMINES
}

EARTH•ENERGY•ENVIRONMENT

DiVISION OF ECONOMICS AND BUSINESS

WORKING PAPER SERIES

\section{Updating Allowance Allocations in Cap-and-Trade: Evidence from the NOx Budget Program}

\author{
Ian Lange \\ Peter Maniloff
}

\author{
Working Paper 2017-01 \\ http://econbus-papers . mines . edu/working-papers/wp201701.pdf \\ Colorado School of Mines \\ Division of Economics and Business \\ 1500 Illinois Street \\ Golden, CO 80401
}

July 2017 
Colorado School of Mines

Division of Economics and Business

Working Paper No. 2017-01

July 2017

Title:

Updating Allowance Allocations in Cap-and-Trade: Evidence from the NOx Budget Program*

Author(s):

Ian Lange

Division of Economics and Business

Colorado School of Mines

Peter Maniloff

Division of Economics and Business

Colorado School of Mines

Golden, CO 80401

manilof $f @ m i n e s . e d u$

\section{ABSTRACT}

The level and distribution of the costs of tradable allowance schemes are important determinants of whether the regulation is ultimately enacted. Theoretical and simulation models have shown that updating allowance allocations based on firm emissions or output can improve the efficiency of the scheme by acting as a production subsidy. Using the U.S. NOx Budget Program (NBP) as a case study, this analysis tests whether power plants in states which chose an updating allocation increase their electricity production relative to plants in states that chose a fixed allocation. Results find that updating allocations led to a 5 percentage point increase in capacity factors for natural gas combined cycle generators and no effect or a modest decrease for coal generators. These findings imply that an updating allocations confers a modest but meaningful subsidy to production relative to a fixed allocation and that firm responses are heterogeneous based on production technology and market conditions.

\section{JEL classifications: Q48, Q58, L94}

Keywords: cap-and-trade, electricity, climate change

* Maniloff is corresponding author. The authors which to thank Harrison Fell, ABB, and seminar and conference participants at Georgia Tech, the 2016 AERE Summer Conference, and the 2016 CU Environmental and Resource Economics Workshop. 


\section{Introduction}

The distributional impacts of tradable permit schemes are an increasingly important part of any political debate over new environmental regulations. Past research has shown that the allocation method for permits is one way to improve the efficiency and alter the incidence of the regulation (Goulder et al. 1999; Fullerton and Metcalf 2001). Permits are often given away freely to regulated firms to meet distributional goals. However, updating that allocation at regular time intervals to reflect each firm's relative share of emissions (or output) has been shown in theoretical and simulation models to be more efficient than a fixed allocation method in some second-best settings. Policymakers have started to widely consider alternatives to grandfathering, with the European Union's Emission Trading Scheme (EU ETS) and California emissions trading system both utilizing an updating allocation.

In this paper, we use the NOx Budget Program (NBP) to econometrically investigate the effect of updating allocations on electricity generators. The effectiveness of updating allocation is particularly interesting to explore given the current movement towards regional cap-and-trade systems which may be particularly vulnerable to leakage or market power.

Our results find that the production subsidy inherent in an updating allocation increase natural gas combined cycle (NGCC) generators' capacity factor (utilization rate) by 5 percentage points or $13 \%$. The production subsidy inherent in an updating allocation is larger than the effect of the emissions cap for NGCC plants. Coal plants, with higher emissions rates, see a small decrease in capacity factor that is not always statistically significant. For coal plants, the production subsidy is not enough to completely offset the impact of the emissions cap. 
A substantial theoretical literature has shown that updating allocation mechanisms can improve welfare when cap-and-trade programs are implemented in second best settings. Updating allocation has been proposed to mitigate concerns about emissions leakage (Fischer and Fox 2012), market power (Gersbach and Requate 2004), trade and tax interaction effects (Fischer and Fox 2007), or uncertainty (Meunier et al. 2016). Updating allocation acts as a production subsidy, which can ameliorate competition from uncapped regions (which leads to leakage) and encourage production (mitigating market power.) Fowlie, Reguant, and Ryan (2016) conduct a counterfactual simulation of an updating policy based on a structural econometric model, finding that updating allocation could address a cap-and-trade program's interactions with the market power concerns identified in Ryan (2012).

While the theoretical literature is promising, the econometric literature on updating allocation mechanisms is quite sparse. Branger et al. (2015) find that cement plants respond to a step-wise allocation system by bunching just above production levels required to receive larger allocations. In a working paper, Fowlie (2010a) also uses the variation in allocation mechanism in the NBP as its testing ground. The outcome tested is whether plant's decision to re-start after being shutdown is affected by the emissions regulation and the production subsidy. Fowlie (2010a) finds that the emissions restrictions lead to longer shutdown times, however the impact of the production subsidy is not consistently statistically different than zero.

A much larger literature analyses production decisions in electricity generation. Coal and gas plants respond to variation in fuel prices, and an increase in the price of either fuel causes substitution to the other (Linn, Muehlenbachs, and Wang 2014; Cullen and Mansur forthcoming). When electricity generators are subject to an emissions price, they reduce their 
emissions level (Stavins 1998; Murray and Maniloff 2015). However, a number of papers find that regional cap-and-trade programs can results in emissions leakage (Fowlie 2009; Fell and Maniloff 2015). Carley (2011) argue that cooperation between states to harmonize their capand-trade systems can help mitigate leakage. However, there is little econometric evidence on the effectiveness of policies to address leakage in the electricity sector.

We make two distinct contributions with this study. First, we provide econometric evidence that plants responded to the implicit price subsidy inherent in an updating allocation. Second, we show that low emissions intensity producers respond more to an updating allocation mechanism that high emissions intensity producers.

These results are instructive for policymakers planning the set-up of a tradable permit scheme. They reveal the magnitude of the production subsidy inherent in an updating allocation; small but substantial enough to see increases in production. Importantly, the results also provide information about the type of plant that changes production and when these changes occur. Plants with higher emissions intensity have their response to the production subsidy muted by the emissions restrictions. The biggest decline for high emissions intensity plants tend to occur in off-peak hours when their is spare generation capacity.

It is worth noting that these results were found during a period of a decreasing price of allowances. If instead an updating allocation mechanism were implemented in a setting with annually increasing emissions prices, firms might be even more responsive to updating allocation.

The next section provides background on the NBP and how power plants can comply with the regulation. Section 3 outlines how we estimate the impact of updating allocations versus the NBP emissions cap using the data discussed in Section 4. Section 5 interprets the 
results of our estimation and Section 6 provide closing remarks on the analysis.

\section{Background}

The NBP was a cap-and-trade system for NOx emissions from fossil fuel plants from 20032008. Nitrogen oxides, typically abbreviated NOx, are a chemical byproduct of burning fossil fuel. Under particular weather conditions (generally, summer), NOx can combine with other atmospheric compounds to form ozone, which is a known hazard to human health.

The NBP capped emissions from plants in the NBP region from May 1 to September 30 of each year. The NBP started in 2003 for plants in northeastern states which were previously regulated under the Ozone Transport Commission ${ }^{1}$. Other states joined the NBP in $2004 .^{2}$

In order to ensure a common market for emissions permits, the EPA drafted a model rule for each state to add to their state implementation plans for pollution control. This model rule included information such as NOx "budgets" for each state and emissions reporting guidelines. Important issues that were common across all states is the compliance period (May 1 to September 30), borrowing was not allowed, and banking was allowed but a mechanism, called progressive flow control, was in place to decrease the value of banked allowances if there were too many. States had substantial discretion regarding how they allocated allowances, and all chose to freely allocate allowances to emitters. The states split their choice of allocation method between a fixed allocation (grandfathering) and an updating allocation.

\footnotetext{
${ }^{1}$ Massachusetts, Connecticut, Rhode Island, New York, New Jersey, Pennsylvania, Maryland, and Delaware

${ }^{2}$ Alabama, Massachusetts, Connecticut, Rhode Island, New York, New Jersey, Pennsylvania, Maryland, Delaware, Ohio, Indiana, Illinois, Michigan, Missouri, Kentucky, Tennessee, Virginia, West Virginia, North Carolina, South Carolina and Georgia. Due to a lawsuit, some states did not join the NBP until May 24, 2004. Those states' compliance windows began on May 1 in subsequent years.
} 
The states that chose updating allocations are: Connecticut, Kentucky, Massachusetts, New Jersey, New York, Pennsylvania, Virginia, and West Virginia. The states which chose a fixed allocation are: Alabama, Delaware, Georgia, Illinois, Indiana, Maryland, Michigan, Missouri, North Carolina, Ohio, Rhode Island, South Carolina, and Tennessee. ${ }^{3}$

A electricity firm wishing to reduce its NOx emissions has two choices: (1) it can reduce generation, (2) it can shift generation from more emissions-intensive sources to less emissions intensive sources, or (2) it can install end-of-pipe or production process technologies to reduce emissions. Linn (2008) has documented that many plants in the NBP have installed combustion control technologies that led to a 10-15\% reduction in NOx emissions. Fowlie (2010b) shows that plants in regulated electricity markets are more likely to install postcombustion technologies given the capital recovery measures in place.

\section{Empirical Strategy}

Our empirical strategy relies on a multiple difference-in-differences approach. For the first difference, we compare capacity factors for plants which are under the NBP and plants which are not. As plants entered the NBP during our study period, we can compare NBP plants before and after the NBP for a difference-in-differences approach.

As an additional difference-in-differences estimate, we can compare NBP plants which were eligible for updating allocations to NBP plants which received fixed allocations. This difference allows us to disentangle the effect of the emissions price and the updating allocation

\footnotetext{
${ }^{3}$ Ideally the choice of allocation mechanism would be random. It is difficult to perform statistical analyses with 21 observations (each state chose their allocation mechanism once). Generally both groups contain a mix of states in terms of geographic size, GDP, and population. The updating states contain the states with high levels of coal production (Kentucky, West Virginia, and Virginia) however the grandfathering states contain Illinois, Indiana, and Ohio, all of which have a moderate amount of coal production.
} 
subsidy.

Finally, we can compare NBP generators' capacity factor before and during the NBP compliance period each year, for an intra-plant comparison. This third difference is akin to a regression discontinuity design in that we will compare the (conditional) capacity factor of a given generator on May 1 to the capacity factor of the same plant on April 30. The identifying assumption is that, controlling for load and other observable factors, generation will be very similar but for the policy change. However, we will use a difference-in-difference approach again here because regression discontinuity estimates are only valid near the cutoff point, and we have no reason to believe that the policy effects will vary during the policy period.

We estimate Equation 1 with a dependent variable of unit capacity factor $C F_{i t}$, the ratio of actual electricity produced to the theoretical maximum amount that could be produced. The treatment indicators $T R E A T_{i t}^{j}$ are 1 if observation it is under treatment $j$ and 0 otherwise. Treatment 1 describes being under the NOx budget plan (during the NOx season) while treatment 2 describes being eligible for updating allowance allocation. We estimate Equation 1 separately for coal and NGCC plants because they respond differently to control variables and may respond differently to treatment effects. NGCC plants tend to be larger and run more often than other types of natural gas plants. ${ }^{4}$

$$
C F_{i t}=\sum_{j \in J} \alpha_{j} T R E A T_{i t}^{j}+\mathbf{X}_{i t}^{\prime} \beta+\gamma_{y}+\sigma_{w o y}+\phi_{h}+\theta_{i}+\mu_{i t}
$$

The vector of control variables $X$ includes natural log of load (a measure of the quantity

\footnotetext{
${ }^{4}$ We do not estimate the impact of our treatment variables on other types of plants such as single cycle natural gas plants or oil plants as they are often smaller and used only for short periods of time during the day to meet peak demand.
} 
of electricity demanded), the level of the Renewable Portfolio Standard in the state the plant is located in, an indicator for whether a plant was previously under the OTC program ${ }^{5}$, and the ratio of local coal and natural gas prices. Finally, we allow for unobserved factors by including fixed effects for year $\gamma_{y}$, week of year $\sigma_{w o y}$, hour of day $\phi_{h}$, and generation unit $\theta_{i}$. Errors are clustered at the plant level in all models.

Our estimate of $\alpha_{1}$ can be interpreted as the Average Treatment Effect on the Treated (ATET) of the NBP compliance costs on generation. Our estimate of $\alpha_{2}$ can be interpreted as the ATET of being eligible for updating allocation on generation.

Next we move from an on/off treatment effects framework to considering the effect of the marginal cost of emissions and marginal benefit of allocation on capacity factors. We calculate a generator-specific measure of the per-kWh cost of compliance with the NBP, represented by $M \pi_{i t}^{1}$ in Equation 2 and described in detail in Section 4 . We also construct a measure of the per-kWh expected marginal revenue from additional updating allocations, represented by $M \pi_{i t}^{2}$ and described in Section 4. For generators which are not under the NBP or not eligible for updating allocations, these variables are zero valued. When we estimate these continuous effects in Equation 2, the continuous variables supplant the previous treatment indicators.

$$
C F_{i t}=\sum_{j \in J} \alpha_{j} M \pi_{i t}^{j}+\mathbf{X}_{i t}^{\prime} \beta+\gamma_{y}+\sigma_{w o y}+\phi_{h}+\theta_{i}+\mu_{i t}
$$

\footnotetext{
${ }^{5}$ The OTC program, as described above, was a tradable permit scheme for northeast and mid-atlantic states which was replaced by the NBP. Generators which were under OTC before the NBP undergo a smaller change in their treatment stringency than non-OTC generators.
} 


\section{Data}

Our primary data set consists of detailed electricity generation data from the United States Energy Information Administration Forms 923 and 860 along with the EPA's Continuous

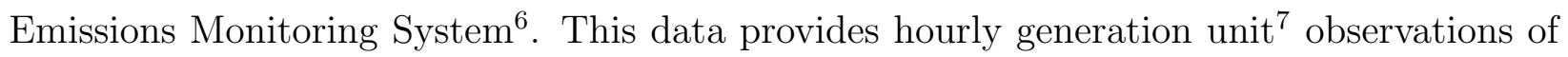
electricity generation as well as a rich set of generator, plant, and regional characteristics. This data covers the years 2003-2008 for plants in the current NEISO, NYISO, PJM, MISO, SPP, and ERCOT regions. These regions, mapped in Figure 1, comprise the deregulated electricity markets in the United States, excepting California. Figure Table 1 lists summary statistics for major variables.

We aggregate generation units' hourly net generation to the daily level and divide by the daily nameplate capacity to calculate the daily capacity factor. Average capacity factors in our sample are $47 \%$ for NGCC plants and $74 \%$ for coal plants. This will be our outcome measure.

\footnotetext{
${ }^{6}$ All data sources we employ were made available by ABB Ventyx via their Velocity Suite data management product, which organizes all publicly available datasets on electricity generating facilities.

${ }^{7}$ An electricity generation unit is a single boiler (or other technology) which produces electricity. A power plant can have multiple generation units. A generation unit typically burns a single primary fuel, while a power plant can have multiple generation units using different fuel types or different technologies.
} 
Figure 1: Map of Independent System Operators and Regional Transmission Organizations

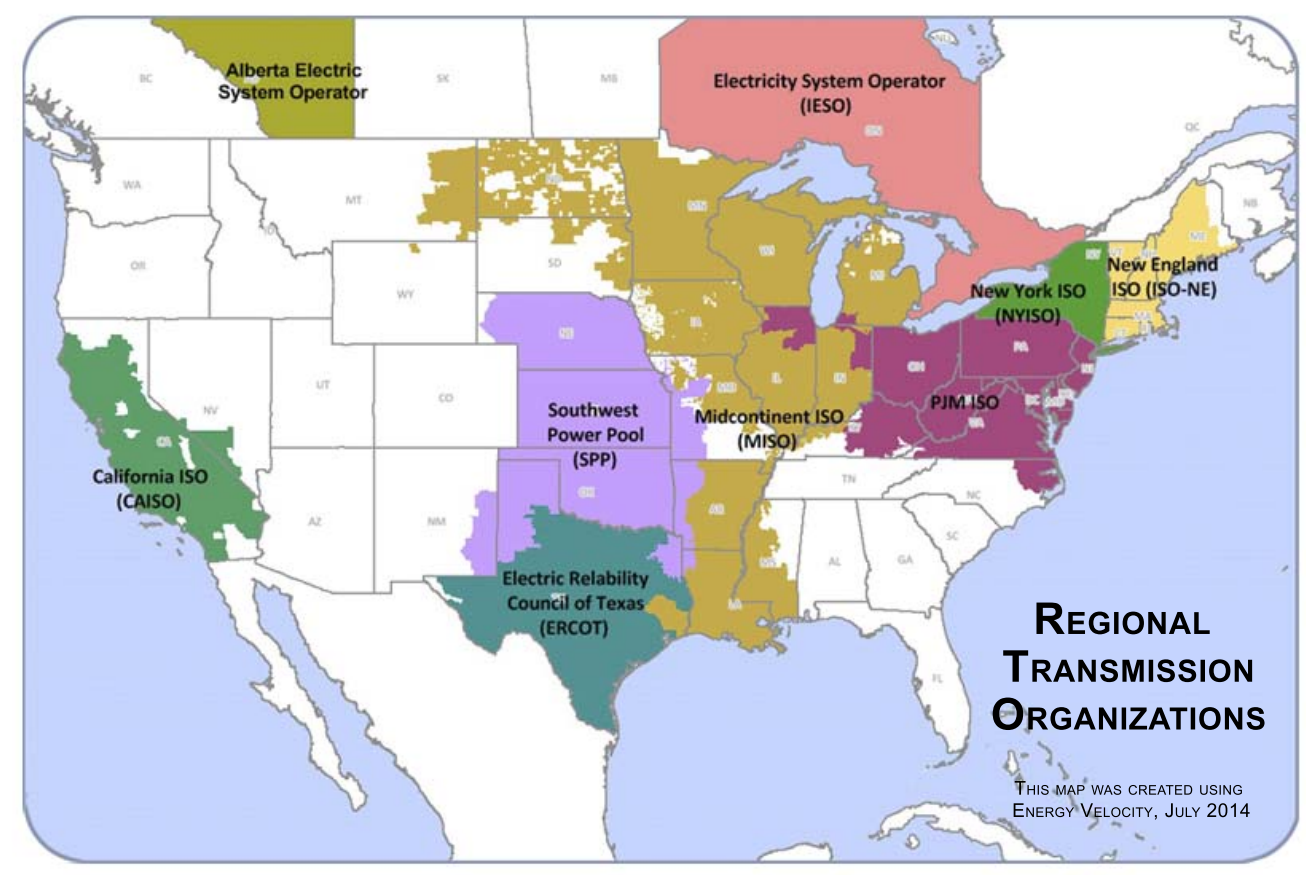

The key determinants of capacity factor are the quantity of electricity demanded (hereafter referred to as load), the marginal cost of generation, and the marginal cost of generation from other plants We observe load at a regional level ${ }^{8}$ and control for it.

We control for marginal cost of both the generation unit's fuel type (coal or gas) and the substitute fuel price (coal for gas plants, gas for coal plants). Fuel is plants' major variable cost, and fuel prices provide the major variance in variable costs.

Approximately 33 percent of coal plant observations and 23 percent of NGCC observations are under the NBP. Approximately 42 percent and 69 percent of these are eligible for

\footnotetext{
${ }^{8}$ We assign plants to ABB Ventyx's "transmission zones" and use daily load in each zone. A "transmission zone" is a pocket of the electricity grid over which load typically rises and falls together.
} 
Table 1: Summary Statistics

\begin{tabular}{|l|cc|}
\hline & NGCC & Coal \\
\hline Capacity Factor & 41.0 & 72.0 \\
& $(22.7)$ & $(22.3)$ \\
Log Load & 8.15 & 8.45 \\
& $(0.745)$ & $(1.05)$ \\
NOx Cost (c/kWh) & 0.0669 & 0.356 \\
(if $>0)$ & $(0.0932)$ & $(.390)$ \\
Updating Subsidy (c/kWh) & 0.394 & 0.324 \\
(if $>0)$ & $(0.267)$ & $(0.256)$ \\
\hline
\end{tabular}

Standard deviations listed in parentheses.

updating allowances. For each group, we calculate the per-kWh cost of purchasing emissions allowances to comply with the NBP as well as the per $\mathrm{kWh}$ subsidy value of updating allocation..$^{9}$

The per kWh cost of the NBP is the NOx allowance price (per ton) multiplied by the emissions rate (emissions per btu) and the heat rate (btu per $\mathrm{kWh}$ ). Figure 2 shows the price of NOx allowances over time. ${ }^{10}$ We use the daily price as a measure of the cost for firms. On days with no trades, we linearly interpolate prices. For each year, we use the price of that year's vintage allowances.

To calculate the subsidy value, we assume that updating states will allocate all allowances on the basis of a generators' share of the previous year's generation. This is a strong simplification - in practice, states tweak this method in a variety of ways, including carving out subsets of allowances to allocate for other purposes such as new entrants. We also assume that firms know what the total generation level will be for the state-year when making gen-

\footnotetext{
${ }^{9}$ We drop several dozen outlying calculated costs or subsidy values more than 10 times the value of the 99th percentile for each fuel. These seem to have mistaken data entries.

${ }^{10}$ Provided by ABB Ventyx.
} 
eration decisions. The value of the subsidy is calculated by dividing the total value of the next year's allocation (the number of allowances times the price of an allowance) by the total annual fossil generation in the state in $\mathrm{kWh} .{ }^{11}$ This describes the per $\mathrm{kWh}$ increase in the value of the next year's allocation for a small generator who marginally increases generation. In the interest of parsimony, we do not discount future values. Results which discount future allotments are similar.

Figure 2: NOx Allowance Prices

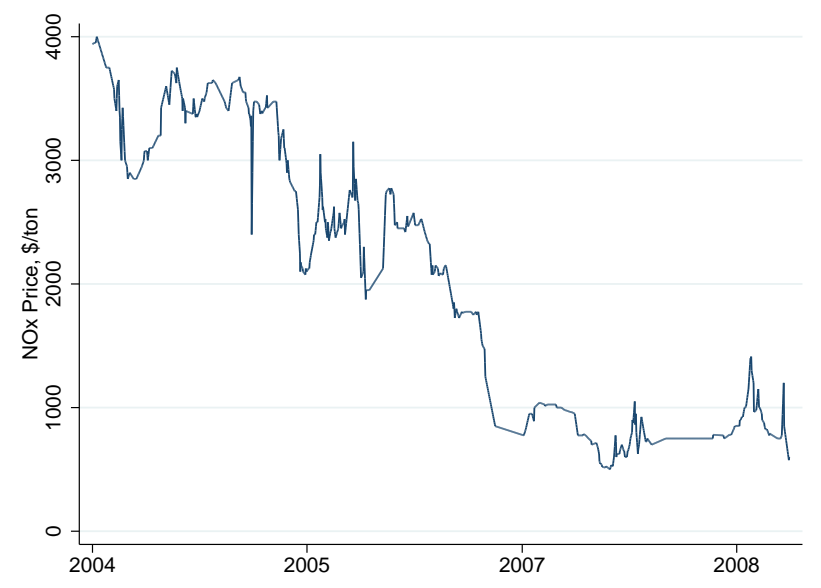

Typical fuel costs for fossil steam plants average about 2-3 cents per kWh (EIA 2016, Table 8.4), so the value of the subsidy is on the order of $5-10 \%$ of fuel costs. It is worth noting that the subsidy of updating allowances modestly outweighs the compliance cost for NGCC plants, while the subsidy is substantially smaller for coal plants. The average value of the subsidy differs for NGCC and coal plants because their distribution across states varies slightly.

We control for fossil fuel prices with a cubic polynomial of the coal-gas price ratio. ${ }^{12}$ For

\footnotetext{
${ }^{11}$ State emissions allowance levels are from the EPA (2008)

${ }^{12}$ Cullen and Mansur (forthcoming) suggest that a nonparametric approach is more appropriate due a "kink point" when gas becomes cheap relative to coal. Our study period ends before fracking had lead to such low gas prices that a kink point existed.
} 
both coal and gas, we take the average of the price (in energy equivalent units) over each transmissions zone - month. ${ }^{13}$

Finally, because of the pseudo-RD approach we are taking with the start of the compliance period each year, we focus on the start of the NOx season by trimming our sample to a small time window before and after the start of NOx season each year. Our primary specification will use a 3 week window before and after the start of each NOx season; we will present results for other windows as robustness checks.

\section{$5 \quad$ Results}

Our primary finding is that NGCC plants increase their generation under NBP updating allocation relative to grandfathered updating allocations. Coal plants decreased their production. While this decrease is not robustly statistically significant, it seems that the updating allocation mechanism lead to substitution from coal to gas plants. Both generation types respond to the NOx compliance costs. The impacts vary with per-kWh cost for each plant type, but only NGCC plants respond to the per-kWh subsidy on the margin. Coal plants reduce production under updating allocation, but do not respond to the subsidy on the margin, suggesting that the updating allocation subsidy leads to more efficient NGCC plants substituting for coal.

The finding that a subsidy reduces generation from coal plants is at first counterintuitive. However, a subsidy which is larger for cleaner NGCC technologies will lead to an increase in production from cleaner plants. If we think that total electricity demand is perfectly

\footnotetext{
${ }^{13}$ As in Footnote 8, transmission zones are local grid areas in which load typically is consistent over the zone.
} 
inelastic and there is no trade, a reasonable short-term approximation, then the increase in NGCC generation would necessarily squeeze out coal generation. Of course, states do trade electricity across state lines, but this simple model suggests that if transmission (trade) is capacity-constrained or costly, the effect of an updating allocation subsidy on emissionsintensive plants is ambiguous.

We present the results of estimating Equations 1 and 2 in Table 2. Columns (1) and (4) present results from Equation 1, while Columns (2) and (5) present results from Equation 2. Columns (3) and (6) include both the program indicators as well as the variable effects. The first two rows include coefficients for the indicator variables for the NBP program and whether a generator is eligible for updating allocations, while rows 3 and 4 include the coefficients on the NBP program cost and updating allocation subsidy value in cents per kWh.

The specifications in Table 2 cluster the error terms at the plant level. However, there may be correlated errors at a state level, or autocorrelation, or other important error structures. Section 5.2.3 reestimates the models of Columns (3) and (6) allowing for other error correlation structures.

NGCC plants respond strongly to the updating allocation: a one cent per kWh subsidy is associated with a 14.38-16.33 percentage point increase in capacity factor. The mean subsidy value is .394 cents (for plants eligible for updating allocations), so the subsidy is associated with a four to five percentage point increase in capacity factor at the mean subsidy, which is about a ten to thirteen percent change in capacity factor.

We also find that coal generation decreases under updating allocation as it is supplanted by less emissions-intensive NGCC generation. Eligibility for updating allocation is associ- 
ated with a 2.246 percentage point decrease in coal generator capacity factors. As this is not precisely related to the magnitude of the subsidy, it seems likely that this reflects displacement. We note from Table 1 that compliance costs exceed the subsidy values for typical coal plants, but that the opposite is true for NGCC plants.

The NBP program cost is associated with reductions in generation from both coal and NGCC plants. We see that a one cent per $\mathrm{kWh}$ cost has a somewhat larger impact on NGCC generation than a one cent per kWh subsidy, although we cannot reject the null hypothesis that the coefficients are equal.

Table 2: Effect of NOx Price and Subsidy on Capacity Factor

Coal NGCC

(1)

\begin{tabular}{|l|ccc|ccc|}
\hline NBP Program & 0.246 & & $2.501^{* * *}$ & -0.316 & & 1.070 \\
& $(0.739)$ & & $(0.848)$ & $(1.952)$ & & $(1.963)$ \\
Updating & $-2.246^{* *}$ & & -1.942 & $3.379^{+}$ & & -2.322 \\
& $(0.996)$ & & $(1.563)$ & $(2.080)$ & & $(2.449)$ \\
NBP cost & & $-6.016^{* * *}$ & $-7.120^{* * *}$ & & $-23.94^{* *}$ & $-24.87^{* *}$ \\
& & $(1.214)$ & $(1.322)$ & & $(11.28)$ & $(11.42)$ \\
Subsidy value & & 0.618 & 1.574 & & $14.38^{* * *}$ & $16.33^{* * *}$ \\
& & $(2.237)$ & $(3.374)$ & & $(2.964)$ & $(4.096)$ \\
\hline Observations & 74979 & 73205 & 73205 & 13594 & 13483 & 13483 \\
\hline
\end{tabular}

Notes: $+{ }^{*},{ }^{* *},{ }^{* * *}$ denote statistical significance at at least the $15,10,5$, and 1 percent levels, respectively. Robust standard errors, clustered at the plant level, are given in parentheses below the parameter estimates. All specifications include a cubic function of the local coal-gas price ratio, natural log of load, RPS level, generator, year, and week of year fixed effects.

\subsection{Peak vs Off-Peak Hours}

Demand for electricity is typically higher during the day versus overnight. This well-known diurnal cycle means that higher cost generation technologies are typically only used during 
Table 3: On and Off Peak Capacity Factors

\begin{tabular}{|lcc|}
\hline & Coal & NGCC \\
Peak & 77.6 & 46.4 \\
Off-peak & 66.6 & 31.5 \\
\hline
\end{tabular}

so-called "peak" hours, and are shut off during overnight "off-peak" hours. In this section, we test whether the effects of the NBP and updating allocation were different during peak and off-peak hours. There are two distinct reasons we might expect differential effects: there is more spare capacity during off-peak hours and different plants are on the margin. In particular, NGCC plants are typically operating during peak hours, and not during off-peak hours. Table 3 describe the average capacity factors for coal and NGCC generators during peak and off-peak hours. We see a fifteen percentage point swing in NGCC generators put differently, during peak hours NGCC capacity factors are fifty percent higher than offpeak. Coal plants also respond to diurnal cycles, but somewhat more modestly as they were primarily used for overnight base-load during the study period.

Tables 4 and 5 describe the results of reestimating our model, but restricting the sample to peak and off-peak hours, respectively. We define peak to be 8AM to 8PM, and off-peak to be $12 \mathrm{AM}-8 \mathrm{AM}$ and $8 \mathrm{PM}-12 \mathrm{AM}$. Point estimates are strikingly similar to the core estimates of Table 2. We see an increase in generation for NGCC plants that is associated with the subsidy value, a reduction in generation from coal plants with the NBP compliance costs, and a reduction in generation from coal plants under updating allocations that is not strongly related to their subsidy value.

The major difference in these subsamples is that NGCC effects appear to be larger during peak periods - we see that the subsidy effect is 15.11 percentage points per kWh during peak 
periods, and only 11.87 during off-peak periods. However, we are unable to reject the null hypothesis that the peak and off-peak effects are equal in magnitude.

Table 4: Peak Hour Effect of NOx Price and Subsidy on Capacity Factor

Coal

(2)

\begin{tabular}{|l|ccc|ccc|}
\hline NBP Program & 0.648 & & $2.892^{* * *}$ & -0.189 & & 1.345 \\
& $(0.753)$ & & $(0.856)$ & $(2.225)$ & & $(2.226)$ \\
Updating & $-1.915^{* *}$ & & -1.634 & 3.253 & & -2.647 \\
& $(0.916)$ & & $(1.562)$ & $(2.391)$ & & $(2.701)$ \\
NBP cost & & $-5.831^{* * *}$ & $-7.188^{* * *}$ & & $-29.38^{*}$ & $-30.77^{*}$ \\
& & $(1.317)$ & $(1.398)$ & & $(16.22)$ & $(16.32)$ \\
Subsidy value & & 1.018 & 1.306 & & $15.11^{* * *}$ & $17.21^{* * *}$ \\
& & $(2.411)$ & $(3.667)$ & & $(3.303)$ & $(4.288)$ \\
\hline Observations & 73810 & 72062 & 72062 & 13328 & 13221 & 13221 \\
\hline
\end{tabular}

Notes: $+,^{*},{ }^{* *},{ }^{* * *}$ denote statistical significance at at least the $15,10,5$, and 1 percent levels, respectively. Robust standard errors, clustered at the plant level, are given in parentheses below the parameter estimates. All specifications include a cubic function of the local coal-gas price ratio, natural log of load, RPS level, generator, year, and week of year fixed effects. 
Table 5: Off-Peak Effect of NOx Price and Subsidy on Capacity Factor

Coal NGCC

\begin{tabular}{|l|ccc|ccc|}
\multicolumn{1}{c}{} & $(1)$ & $(2)$ & $(3)$ & $(4)$ & $(5)$ & $(6)$ \\
\hline NBP Program & -0.234 & & $1.764^{* *}$ & -1.271 & & -0.163 \\
& $(0.729)$ & & $(0.803)$ & $(1.706)$ & & $(1.754)$ \\
Updating & $-2.182^{* *}$ & & -1.767 & 2.548 & & -2.435 \\
& $(1.031)$ & & $(1.543)$ & $(1.925)$ & & $(2.583)$ \\
NBP cost & & $-5.579^{* * *}$ & $-6.311^{* * *}$ & & $-19.08^{* * *}$ & $-18.24^{* *}$ \\
& & $(0.946)$ & $(1.022)$ & & $(6.991)$ & $(7.521)$ \\
Subsidy value & & 0.398 & 1.601 & & $11.87^{* * *}$ & $15.19^{* * *}$ \\
& & $(2.113)$ & $(3.170)$ & & $(3.319)$ & $(4.961)$ \\
\hline Observations & 74833 & 73060 & 73060 & 12933 & 12827 & 12827 \\
\hline
\end{tabular}

Notes: $+{ }^{*},{ }^{* *},{ }^{* * *}$ denote statistical significance at at least the $15,10,5$, and 1 percent levels, respectively. Robust standard errors, clustered at the plant level, are given in parentheses below the parameter estimates. All specifications include a cubic function of the local coal-gas price ratio, natural log of load, RPS level, generator, year, and week of year fixed effects.

\subsection{Robustness checks}

In this section we explore the robustness of our results. We will test robustness whether firms use the contemporaneous or future prices of NOx in calculating future allowance allocation values, robustness to the time window around the program start, and robustness to the model of unobservable errors.

\subsubsection{NOx Allowance Price Futures}

First we test whether our results hold if firms were able to accurately project future NOx allowance prices in their consideration of the value of a future contingent allocation. Allowances were bankable under the NBP, within some limits as discussed above, so a firm observing large banks might have forseen future price decreases. In Table 6 , we report the results of reestimating Equation 2 with the one year ahead NBP prices in the place of con- 
temporary prices in our calculation of the marginal subsidy value. For ease of use, we also re-report results from Table 2 in columns (1) and (4). We see consistent signs and significance, with a larger subsidy effect for NGCC plants. NOx prices declined through most of our study period, so future prices are generally lower than contemporary prices. Thus a larger magnitude effect is to be expected.

Table 6: Robustness to Using Year-Ahead NOx Value

\begin{tabular}{|c|c|c|c|c|c|c|}
\hline & \multicolumn{3}{|c|}{ Coal } & \multicolumn{3}{|c|}{ NGCC } \\
\hline & (1) & $(2)$ & (3) & (4) & (5) & (6) \\
\hline NBP Program & $\begin{array}{c}2.501^{* * *} \\
(0848)\end{array}$ & & $\begin{array}{c}2.493^{* * *} \\
(0.845)\end{array}$ & $\begin{array}{c}1.070 \\
(1.963)\end{array}$ & & $\begin{array}{c}0.832 \\
(1.975)\end{array}$ \\
\hline Updating & $\begin{array}{l}-1.942 \\
(1.563)\end{array}$ & & $\begin{array}{l}-1.225 \\
(1.843)\end{array}$ & $\begin{array}{l}-2.322 \\
(2.449)\end{array}$ & & $\begin{array}{l}-1.108 \\
(2.982)\end{array}$ \\
\hline NBP cost & $\begin{array}{c}-7.120^{* * *} \\
(1.322)\end{array}$ & $\begin{array}{c}-6.067^{* * *} \\
(1.222)\end{array}$ & $\begin{array}{c}-7.245^{* * *} \\
(1.346)\end{array}$ & $\begin{array}{c}-24.87^{* *} \\
(11.42)\end{array}$ & $\begin{array}{c}-25.22^{* *} \\
(10.47)\end{array}$ & $\begin{array}{c}-26.09^{* *} \\
(10.44)\end{array}$ \\
\hline Subsidy value & $\begin{array}{c}1.574 \\
(3.374)\end{array}$ & & & $\begin{array}{c}16.33^{* * *} \\
(4.096)\end{array}$ & & \\
\hline Next year subsidy value & & $\begin{array}{c}2.719 \\
(3.183)\end{array}$ & $\begin{array}{c}2.660 \\
(5.059)\end{array}$ & & $\begin{array}{c}18.51^{* * *} \\
(4.294)\end{array}$ & $\begin{array}{c}19.20^{* * *} \\
(6.723)\end{array}$ \\
\hline Observations & 73205 & 69047 & 69047 & 13483 & 12490 & 12490 \\
\hline
\end{tabular}

\subsubsection{Time Window}

Our core specifications used a window of three weeks before and after the start of each NOx season. This is chosen in somewhat ad-hoc fashion. Here we estimate our core model for broader and narrower window of time before and after the start of NOx season and see that the results are quite similar. Table 7 uses a ten day window on either side of the program start date, while Table 8 uses a six week window. Results for the 10-day window 
are quite similar to those in Table 2 - NGCC plants increase their capacity factors by about 14 percentage points per cent of subsidy, coal plants reduce their capacity factors by about 5 percentage points per cent of subsidy, and coal plants under updating allocation reduce capacity factors by about 2 percentage points.

Specifications using a six week window have a substantially larger sample size ${ }^{14}$. Point estimates and significance are qualitatively similar to estimates from Table 2, although generally smaller. However, we cannot reject the null that the NGCC updating coefficients are equal to those from Table 2. In addition, we cannot reject the null hypothesis that the effect of a one cent per kWh subsidy and one cent per kWh cost have equal effects on NGCC generators.

Table 7: Effect of NOx Price and Subsidy on Capacity Factor: 10 day window Coal $(2)$ NGCC

\begin{tabular}{|l|ccc|ccc|}
\hline NBP Program & $0.889^{+}$ & & $2.771^{* * *}$ & 1.331 & & 2.097 \\
& $(0.611)$ & & $(0.787)$ & $(2.205)$ & & $(2.272)$ \\
Updating & $-2.081^{* *}$ & & -0.829 & 1.951 & & -0.490 \\
& $(0.942)$ & & $(1.374)$ & $(2.203)$ & & $(2.655)$ \\
NBP cost & & $-5.421^{* * *}$ & $-6.873^{* * *}$ & & -13.60 & -18.20 \\
& & $(1.536)$ & $(1.644)$ & & $(15.20)$ & $(15.75)$ \\
Subsidy value & & -0.212 & -0.983 & & $11.17^{* * *}$ & $9.718^{* *}$ \\
& & $(2.863)$ & $(3.934)$ & & $(3.052)$ & $(4.216)$ \\
\hline Observations & 35017 & 34164 & 34164 & 6079 & 6017 & 6017 \\
\hline
\end{tabular}

Notes: $+,^{*}, * *, * * *$ denote statistical significance at at least the $15,10,5$, and 1 percent levels, respectively. Robust standard errors, clustered at the plant level, are given in parentheses below the parameter estimates. All specifications include a cubic function of the local coal-gas price ratio, natural log of load, RPS level, generator, year, and week of year fixed effects.

\footnotetext{
${ }^{14}$ We cluster errors at the plant level, so the increase in sample size primarily means more observations per cluster.
} 
Table 8: Effect of NOx Price and Subsidy on Capacity Factor: Six week window

Coal

NGCC

(1)

(2)

$(3)$

\begin{tabular}{|l|ccc|ccc|}
\hline NBP Program & -0.153 & & 0.391 & $2.530^{+}$ & & $3.176^{*}$ \\
& $(0.650)$ & & $(0.648)$ & $(1.660)$ & & $(1.737)$ \\
Updating & $-1.770^{* *}$ & & -1.405 & 0.763 & & -2.961 \\
& $(0.828)$ & & $(1.192)$ & $(1.833)$ & & $(2.151)$ \\
NBP cost & & $-1.655^{* * *}$ & $-1.659^{* * *}$ & & $-13.84^{* *}$ & $-15.00^{* *}$ \\
& & $(0.246)$ & $(0.249)$ & & $(5.353)$ & $(5.803)$ \\
Subsidy value & & -0.0593 & 1.476 & & $11.40^{* * *}$ & $11.82^{* * *}$ \\
& & $(1.553)$ & $(2.344)$ & & $(2.930)$ & $(3.800)$ \\
\hline Observations & 148924 & 145460 & 145460 & 27882 & 27648 & 27648 \\
\hline
\end{tabular}

(5)

Notes: $+{ }^{*},{ }^{* *},{ }^{* * *}$ denote statistical significance at at least the $15,10,5$, and 1 percent levels, respectively. Robust standard errors, clustered at the plant level, are given in parentheses below the parameter estimates. All specifications include a cubic function of the local coal-gas price ratio, natural log of load, RPS level, generator, year, and week of year fixed effects.

\subsubsection{Additional Error Structures}

Here we reestimate our primary model with several different error structures. First, we cluster errors at the state level to allow for correlation induced by other policies or measurement error. These results are in Columns (1) and (4). Next, we allow for an AR(1) process in the error term. These results, including the autocorrelation coefficient, are in columns (2) and (5). Finally we bootstrap standard errors with 1000 repetitions. These results are in columns (3) and (6). The results are quite similar to our core results of Table 2. A notable distinction is the autoregressive model for coal generators (Column (2)) finds a statistically significant positive effect of the per $\mathrm{kWh}$ subsidy. 
Table 9: Additional Error Structures

\begin{tabular}{|c|c|c|c|c|c|c|}
\hline & \multicolumn{3}{|c|}{ Coal } & \multicolumn{3}{|c|}{ NGCC } \\
\hline & (1) & $(2)$ & $(3)$ & (4) & $(5)$ & (6) \\
\hline \multirow[t]{2}{*}{ NBP Program } & $2.501^{* *}$ & 0.123 & $2.501^{* * *}$ & 1.070 & 1.635 & 1.070 \\
\hline & $(0.972)$ & $(0.464)$ & $(0.735)$ & $(2.212)$ & $(1.257)$ & $(1.929)$ \\
\hline \multirow[t]{2}{*}{ NBP cost } & $-7.120^{* * *}$ & $-5.605^{* * *}$ & $-7.120^{* * *}$ & $-24.87^{*}$ & $-33.39^{* * *}$ & $-24.87^{* *}$ \\
\hline & $(1.647)$ & $(0.310)$ & $(1.126)$ & $(13.92)$ & $(3.543)$ & $(11.19)$ \\
\hline \multirow[t]{2}{*}{ Updating } & -1.942 & -1.202 & $-1.942^{+}$ & -2.322 & $-3.244^{*}$ & -2.322 \\
\hline & $(1.523)$ & $(0.846)$ & $(1.189)$ & $(2.444)$ & $(1.739)$ & $(2.462)$ \\
\hline \multirow[t]{2}{*}{ Subsidy value } & 1.574 & $3.795^{* *}$ & 1.574 & $16.33^{* * *}$ & $12.98^{* * *}$ & $16.33^{* * *}$ \\
\hline & $(2.241)$ & $(1.812)$ & $(2.726)$ & $(4.895)$ & $(3.012)$ & $(4.087)$ \\
\hline \multirow[t]{2}{*}{ Error Structure } & $\begin{array}{l}\text { Clustered } \\
\text { by State }\end{array}$ & $\mathrm{AR}(1)$ & Bootstrap & $\begin{array}{l}\text { Clustered } \\
\text { by State }\end{array}$ & $\operatorname{AR}(1)$ & Bootstrap \\
\hline & & 0.736 & & & 0.770 & \\
\hline
\end{tabular}

\section{Conclusions}

Regional policies are currently the primary mechanism of addressing greenhouse gas emissions. However, regional cap-and-trade systems can lead to emissions leakage and exacerbate market power due to their smaller geographic scope. One proposed solution to address leakage and market power is updating or contingent allocation mechanisms, in which capand-trade allowances distributions depend on firms' actions.

We provide econometric evidence that electricity generators do respond to updating allocation mechanisms. More specifically, we use generator-level data and a multiple differencein-difference approach to econometrically estimate the impact of the NOx Budget Plan on generator's decisions. The NBP used a mixture of updating and fixed allocation mechanisms, allowing us to disentangle the effect of the emissions constraint from the effect of the updating allocation. 
Our analysis finds that an updating allocation led to about a five percentage point increase in capacity factors for lower polluting natural gas plants. We also find some evidence of a modest reduction in generation from coal plants under updating allocations, suggesting that the updating allocation may have led coal plants to be supplanted by less emissions-intensive gas generation. The net effect is an increase in electricity generation of approximately five percent.

Taken together, these results show that firms do respond to contingent allocation mechanisms as proposed in theoretical work (Fischer and Fox 2007; Fischer and Fox 2012; Gersbach and Requate 2004). Particularly in light of recent evidence of leakage from both national and subnational cap-and-trade systems (Aichele and Felbermayr 2015; Fell and Maniloff 2015), these policies may be an effective tool for environmental policymaking in a secondbest setting. However, the precise response varies by facility and market characteristics. This suggests that more research on sectoral, environmental, and economic impacts of these policies, particularly in light of the large shifts in electricity generation brought on by the fracking revolution and recent increases in renewable generation. 


\section{References}

Aichele, R. And G. Felbermayr (2015): "Kyoto and carbon leakage: An empirical analysis of the carbon content of bilateral trade," Review of Economics and Statistics, 97, 104-115.

Branger, F., J.-P. Ponssard, O. Sartor, and M. Sato (2015): "EU ETS, Free Allocations, and Activity Level Thresholds: The Devil Lies in the Details," Journal of the Association of Environmental and Resource Economists, 2, 401-437.

Carley, S. (2011): "Decarbonization of the US electricity sector: Are state energy policy portfolios the solution?" Energy Economics, 33, 1004-1023.

Cullen, J. And E. Mansur (forthcoming): "Inferring Carbon Abatement Costs in Electricity Markets: A Revealed Preference Approach Using the Shale Revolution," American Economic Journal:Economic Policy.

EIA (2016): "Electric Power Annual 2015," Tech. rep.

EPA (2008): "The NOx Budget Trading Program: 2008 Emission, Compliance, and Market Analysis," Tech. rep.

Fell, H. And P. Maniloff (2015): "Beneficial Leakage: The Effect of the Regional Greenhouse Gas Initiative on Aggregate Emissions," Tech. rep.

Fischer, C. And A. Fox (2007): "Output-based Allocation of Emissions Permits for Mitigating Tax and Trade Interactions," Land Economics, 83, 575-599.

- (2012): "Comparing policies to combat emissions leakage: Border carbon adjustments versus rebates," Journal of Environmental Economics and Management, 
64, 199-216.

Fowlie, M. (2010a): "Allocating emissions permits in cap-and-trade programs: Theory and evidence," .

Fowlie, M., M. Reguant, and S. Ryan (2016): "Market-Based Emissions Regulation and Industry Dynamics," Journal of Political Economy, 124, 249-302.

FOwLIE, M. L. (2009): "Incomplete environmental regulation, imperfect competition, and emissions leakage," American Economic Journal: Economic Policy, 1, 72-112.

(2010b): "Emissions trading, electricity restructuring, and investment in pollution abatement," American Economic Review, 100, 837-869.

Fullerton, D. and G. Metcalf (2001): "Environmental Controls, Scarcity Rents, and Pre-existing Distortions," Journal of Public Economics, 80, 249-267.

Gersbach, H. and T. Requate (2004): "Emission taxes and optimal refunding schemes," Journal of Public Economics, 88, 713 - 725.

Goulder, L., I. Parry, R. Williams, and D. Burtraw (1999): "The Costeffectiveness of Alternative Instruments for Environmental Protection in a Secondbest Setting," Journal of Public Economics, 72, 329 -360.

Linn, J. (2008): "Technological Modifications in the Nitrogen Oxides Tradable Permit Program," The Energy Journal, 29, 153-176.

Linn, J., L. Muehlenbachs, And Y. Wang (2014): "How Do Natural Gas Prices Affect Electricity Consumers and the Environment?" Tech. rep.

Meunier, G., J.-P. Montero, And J.-P. Ponssard (2016): "Output-based Alloca- 
tions in Pollution Markets with Uncertainty and Self-selection," Catholic University of Chile Economic Institute Working Paper 476.

Murray, B. C. And P. T. Maniloff (2015): "Why have greenhouse emissions in RGGI states declined? An econometric attribution to economic, energy market, and policy factors," Energy Economics, 51, 581-589.

RYAN, S. P. (2012): "The costs of environmental regulation in a concentrated industry," Econometrica, 80, 1019-1061.

Stavins, R. N. (1998): "What can we learn from the grand policy experiment? Lessons from SO 2 allowance trading," The Journal of Economic Perspectives, 69-88. 


\section{A Additional Controls}

Table 10 lists the control variables from the regressions described in Table 2. Point estimates are generally as expected. A one percent increase in load is associated with a 0.31-0.32 percentage point increase in capacity factor from coal plants, and a 0.43-0.44 percentage point increase in capacity factor from gas plants. 
Table 10: Effect of NOx Price and Subsidy on Capacity Factor

\begin{tabular}{|c|c|c|c|c|c|c|}
\hline & (1) & $\begin{array}{c}\text { Coal } \\
(2)\end{array}$ & (3) & $(4)$ & $\begin{array}{c}\text { NGCC } \\
(5)\end{array}$ & (6) \\
\hline $\ln ($ load $)$ & $\begin{array}{c}31.93^{* * *} \\
(2.441)\end{array}$ & $\begin{array}{c}31.19^{* * *} \\
(2.399)\end{array}$ & $\begin{array}{c}31.70^{* * *} \\
(2.389)\end{array}$ & $\begin{array}{c}44.25^{* * *} \\
(4.975)\end{array}$ & $\begin{array}{c}43.04^{* * *} \\
(4.691)\end{array}$ & $\begin{array}{c}42.84^{* * *} \\
(4.711)\end{array}$ \\
\hline RPS & $\begin{array}{l}-7.582 \\
(24.37)\end{array}$ & $\begin{array}{l}-8.319 \\
(25.07)\end{array}$ & $\begin{array}{l}-2.334 \\
(24.72)\end{array}$ & $\begin{array}{l}-42.29 \\
(76.58)\end{array}$ & $\begin{array}{l}-28.96 \\
(74.55)\end{array}$ & $\begin{array}{l}-28.08 \\
(74.52)\end{array}$ \\
\hline coal/gas & $\begin{array}{l}-33.00 \\
(56.50)\end{array}$ & $\begin{array}{l}-66.72 \\
(58.55)\end{array}$ & $\begin{array}{l}-58.85 \\
(58.27)\end{array}$ & $\begin{array}{c}136.5 \\
(140.9)\end{array}$ & $\begin{array}{c}119.1 \\
(142.9)\end{array}$ & $\begin{array}{c}121.3 \\
(141.6)\end{array}$ \\
\hline$(\text { coal/gas })^{2}$ & $\begin{array}{c}77.56 \\
(219.0)\end{array}$ & $\begin{array}{c}227.7 \\
(230.5)\end{array}$ & $\begin{array}{c}190.9 \\
(229.2)\end{array}$ & $\begin{array}{l}-6.662 \\
(506.1)\end{array}$ & $\begin{array}{c}37.49 \\
(524.6)\end{array}$ & $\begin{array}{c}28.00 \\
(519.4)\end{array}$ \\
\hline$(\text { coal/gas })^{3}$ & $\begin{array}{l}-69.72 \\
(243.9)\end{array}$ & $\begin{array}{l}-234.0 \\
(260.3)\end{array}$ & $\begin{array}{l}-189.3 \\
(258.8)\end{array}$ & $\begin{array}{l}-306.2 \\
(540.5)\end{array}$ & $\begin{array}{l}-350.8 \\
(564.2)\end{array}$ & $\begin{array}{l}-341.4 \\
(559.0)\end{array}$ \\
\hline OTC & $\begin{array}{c}-0.0605 \\
(2.331)\end{array}$ & $\begin{array}{c}0.398 \\
(2.533)\end{array}$ & $\begin{array}{l}-0.172 \\
(2.577)\end{array}$ & $\begin{array}{l}5.757^{*} \\
(3.102)\end{array}$ & $\begin{array}{l}7.466^{* *} \\
(3.181)\end{array}$ & $\begin{array}{l}7.757^{* *} \\
(3.220)\end{array}$ \\
\hline week 15 & $\begin{array}{c}-1.406^{* * *} \\
(0.364)\end{array}$ & $\begin{array}{c}-1.458^{* * *} \\
(0.377)\end{array}$ & $\begin{array}{c}-1.453^{* * *} \\
(0.377)\end{array}$ & $\begin{array}{c}-0.382 \\
(0.627)\end{array}$ & $\begin{array}{l}-0.419 \\
(0.625)\end{array}$ & $\begin{array}{c}-0.403 \\
(0.629)\end{array}$ \\
\hline week 16 & $\begin{array}{c}-1.280^{* * *} \\
(0.400)\end{array}$ & $\begin{array}{c}-1.355^{* * *} \\
(0.405)\end{array}$ & $\begin{array}{c}-1.352^{* * *} \\
(0.404)\end{array}$ & $\begin{array}{c}-1.731^{* *} \\
(0.736)\end{array}$ & $\begin{array}{c}-1.634^{* *} \\
(0.723)\end{array}$ & $\begin{array}{c}-1.613^{* *} \\
(0.714)\end{array}$ \\
\hline week 17 & $\begin{array}{c}-2.538^{* * *} \\
(0.518)\end{array}$ & $\begin{array}{c}-2.345^{* * *} \\
(0.482)\end{array}$ & $\begin{array}{c}-2.883^{* * *} \\
(0.521)\end{array}$ & $\begin{array}{c}-2.816^{* * *} \\
(0.945)\end{array}$ & $\begin{array}{c}-2.577^{* * *} \\
(0.843)\end{array}$ & $\begin{array}{c}-2.476^{* * *} \\
(0.877)\end{array}$ \\
\hline week 18 & $\begin{array}{c}-3.280^{* * *} \\
(0.562)\end{array}$ & $\begin{array}{c}-2.887^{* * *} \\
(0.517)\end{array}$ & $\begin{array}{c}-3.665^{* * *} \\
(0.553)\end{array}$ & $\begin{array}{c}-3.635^{* * *} \\
(1.064)\end{array}$ & $\begin{array}{c}-3.248^{* * *} \\
(0.950)\end{array}$ & $\begin{array}{c}-3.099^{* * *} \\
(0.982)\end{array}$ \\
\hline week 19 & $\begin{array}{c}-4.215^{* * *} \\
(0.652)\end{array}$ & $\begin{array}{c}-3.804^{* * *} \\
(0.598)\end{array}$ & $\begin{array}{c}-4.582^{* * *} \\
(0.644)\end{array}$ & $\begin{array}{c}-6.010^{* * *} \\
(1.153)\end{array}$ & $\begin{array}{c}-5.556^{* * *} \\
(1.070)\end{array}$ & $\begin{array}{c}-5.402^{* * *} \\
(1.071)\end{array}$ \\
\hline week 20 & $\begin{array}{c}-4.866^{* * *} \\
(0.776)\end{array}$ & $\begin{array}{c}-4.437^{* * *} \\
(0.719)\end{array}$ & $\begin{array}{c}-5.269^{* * *} \\
(0.774)\end{array}$ & $\begin{array}{c}-5.355^{* * *} \\
(1.259)\end{array}$ & $\begin{array}{c}-4.960^{* * *} \\
(1.173)\end{array}$ & $\begin{array}{c}-4.820^{* * *} \\
(1.184)\end{array}$ \\
\hline week 21 & $\begin{array}{c}-6.649^{* * *} \\
(1.192)\end{array}$ & $\begin{array}{c}-4.723^{* * *} \\
(1.214)\end{array}$ & $\begin{array}{c}-6.030^{* * *} \\
(1.251)\end{array}$ & $\begin{array}{c}-7.688^{* * *} \\
(1.470)\end{array}$ & $\begin{array}{c}-7.644^{* * *} \\
(1.274)\end{array}$ & $\begin{array}{c}-7.631^{* * *} \\
(1.359)\end{array}$ \\
\hline week 22 & $\begin{array}{c}-7.158^{* * *} \\
(1.499)\end{array}$ & $\begin{array}{c}-5.261^{* * *} \\
(1.417)\end{array}$ & $\begin{array}{c}-6.622^{* * *} \\
(1.516)\end{array}$ & $\begin{array}{c}-9.261^{* * *} \\
(1.626)\end{array}$ & $\begin{array}{c}-9.059^{* * *} \\
(1.373)\end{array}$ & $\begin{array}{c}-9.048^{* * *} \\
(1.461)\end{array}$ \\
\hline week 23 & $\begin{array}{c}-8.003^{* * *} \\
(1.499)\end{array}$ & $\begin{array}{c}-6.066^{* * *} \\
(1.441)\end{array}$ & $\begin{array}{c}-7.458^{* * *} \\
(1.521)\end{array}$ & $\begin{array}{c}-9.926^{* * *} \\
(1.737)\end{array}$ & $\begin{array}{c}-9.820^{* * *} \\
(1.608)\end{array}$ & $\begin{array}{c}-9.804^{* * *} \\
(1.707)\end{array}$ \\
\hline 2004 & $\begin{array}{c}0.541 \\
(0.814)\end{array}$ & $\begin{array}{l}1.871^{* *} \\
(0.848)\end{array}$ & $\begin{array}{l}1.696^{* *} \\
(0.818)\end{array}$ & $\begin{array}{c}7.196^{* * *} \\
(2.369)\end{array}$ & $\begin{array}{c}6.533^{* * *} \\
(2.079)\end{array}$ & $\begin{array}{c}6.472^{* * *} \\
(2.065)\end{array}$ \\
\hline 2005 & $\begin{array}{c}-1.604^{*} \\
(0.969)\end{array}$ & $\begin{array}{c}0.256 \\
(0.976)\end{array}$ & $\begin{array}{l}-0.370 \\
(1.023)\end{array}$ & $\begin{array}{c}15.06^{* * *} \\
(2.830)\end{array}$ & $\begin{array}{c}14.64^{* * *} \\
(2.658)\end{array}$ & $\begin{array}{c}14.60^{* * *} \\
(2.664)\end{array}$ \\
\hline 2006 & $\begin{array}{l}-0.989 \\
(0.865)\end{array}$ & $\begin{array}{c}0.585 \\
(0.892)\end{array}$ & $\begin{array}{r}-0.0797 \\
(0.929)\end{array}$ & $\begin{array}{c}10.20^{* * *} \\
(2.848)\end{array}$ & $\begin{array}{c}9.927^{* * *} \\
(2.811)\end{array}$ & $\begin{array}{c}9.893^{* * *} \\
(2.820)\end{array}$ \\
\hline 2007 & $\begin{array}{l}-0.558 \\
(0.973)\end{array}$ & $\begin{array}{c}0.709 \\
(0.998)\end{array}$ & $\begin{array}{c}-0.0799 \\
(1.024)\end{array}$ & $\begin{array}{c}12.59^{* * *} \\
(2.854)\end{array}$ & $\begin{array}{c}12.34^{* * *} \\
(2.831)\end{array}$ & $\begin{array}{c}12.31^{\text {*** }} \\
(2.838)\end{array}$ \\
\hline 2008 & $\begin{array}{c}-2.536^{* *} \\
(0.999)\end{array}$ & $\begin{array}{l}-1.194 \\
(0.970)\end{array}$ & $\begin{array}{c}-2.011^{*} \\
(1.039)\end{array}$ & $\begin{array}{c}14.97^{* * *} \\
(3.155)\end{array}$ & $\begin{array}{c}14.65^{* * *} \\
(3.047)\end{array}$ & $\begin{array}{c}14.63^{* * *} \\
(3.063)\end{array}$ \\
\hline Constant & $\begin{array}{c}-190.2^{* * *} \\
(20.92)\end{array}$ & $\begin{array}{c}-182.8^{* * *} \\
(20.81)\end{array}$ & $\begin{array}{c}-187.0^{* * *} \\
(20.56)\end{array}$ & $\begin{array}{c}-353.1^{* * *} \\
(44.32)\end{array}$ & $\begin{array}{c}-340.9^{* * *} \\
(40.72)\end{array}$ & $\begin{array}{c}-339.4^{* * *} \\
(40.94)\end{array}$ \\
\hline Observations & 74979 & 73205 & 73205 & 13594 & 13483 & 13483 \\
\hline
\end{tabular}

